\title{
Evaluation of Service Quality Gaps in Traditional Appliance Retail using Cause-and- Effect Matrix and Service Failure-mode-and- Effect Analysis Techniques with Case Studies
}

\author{
Chien-Chih Wang ${ }^{1}$, Michael Lin ${ }^{2}$ \\ ${ }^{1}$ Department of Industrial Engineering and Management, Ming Chi University of Technology, Taiwan \\ ${ }^{2}$ I-Sheng Electronics Co., Ltd. , Taiwan
}

\begin{abstract}
With the advent of the new retail era, the traditional home appliance retail market is at a critical stage of transformation. The practical problem is the lack of understanding the consumers' psychological needs leading to gaps in service quality. In this study, a new service gap index was proposed using the $C \& E$ matrix and FMEA to assess the need to adjust the service process. Researchers collected and analyzed data from 150 external questionnaires in New Taipei City. From the report, the service gap index is $\mathbf{- 0 . 6 6}$, indicating that the traditional retail equipment market is in a state of declining service quality. Results show that the service gap index can indicate service bottlenecks and improve process knowledge of service providers.
\end{abstract}

Keywords - critical-to-quality, process analysis, questionnaire analysis, service quality.

\section{Introduction}

Service is an interaction between a provider of production value and the recipient of such value. Everything in daily life, including food, clothing, housing, transportation, education, and entertainment, is a service.

DOI: 10.18421/TEM92-49

https://doi.org/10.18421/TEM92-49

Corresponding author: Chien-Chih Wang,

Ming Chi University of Technology.

Email: ieccwang@mail.mcut.edu.tw

Received: 13 February 2020.

Revised: 02 April 2020.

Accepted: 07 April 2020.

Published: 27 May 2020.

(c)) BY-NC-ND (C) 2020 Chien-Chih Wang \& Michael Lin; published by UIKTEN. This work is licensed under the Creative Commons Attribution-NonCommercial-NoDerivs 3.0 License.

The article is published with Open Access at www.temjournal.com
Service providers firstly have to understand consumers' needs to meet their expectations. Poor service quality refers to a gap between expected result of service and the reality of that service. Although Parasuraman, Zeithaml, and Berry (1988) proposed a service mode for discussion and exploration, this study found the gap formed between service procedures is mainly caused by failures to meet customer demands [9]. Here a service procedure framework was chosen as the background for developing this service gap assessment using the service process concept proposed by Klischewski and Wetzel (2000), who posited that the service process is a series of linked service points interacting with each other and service tasks are actions performed at each of these service points [4].

The biggest problem for service providers is that they are unable to systematically design a service process acceptable by both themselves and the consumer. Service process is special and includes intangible activities, through which problems can be solved for customers so that they are pleased and satisfied. Procedure design directly affects efficiency and service modes. Procedures are a series of interlinked practices adding value to a specific goal or outcome. From the customer satisfaction's perspective, business operations have to focus on the overall process of customer-centric activities and on providing a high degree of customer satisfaction [5], [7], [8]. Lovelock (1991) suggested that when customers perform, the delivery service becomes a distribution process, through which greater convenience and value than the original goods or services can be created [1], [2], [6]. Gronroos (1994) suggested that the consumer service process is made up of a series of activities aimed to solve problems for consumers [3]. Although somewhat intangible, these problems usually arise in the interaction between the customers, and staff of the service provider, physical resources, goods, or systems. Porter (1985) suggested that the enterprise's 
provision of products or services to customers is achieved by a series of combined events that create value [10].

In the face of competition from chain stores, improving the service gap to enhance the market competitiveness of Taiwan's traditional retail home appliance service industry is an important topic. One advantage of supermarket chains is the adoption of volume purchasing, such that pricing is much lower than that of traditional retail appliance service providers. Chain stores sell a wide variety of everyday goods, which leads consumers to buy the appliances they need for their convenience. Moreover, consumers can choose and compare from various home appliances' brands. Prices at supermarket chain stores are transparent, and they also offer on-the-spot professional introductions, and after-sales service mechanisms, such as free replacement during the product trial period. This makes consumers accustomed to the mentality of price comparison and the convenience of online home delivery. The traditional retail appliance industry is facing a crisis of transformation because it is unaware of how to highlight its positive characteristics to win the consumers' favour.

This study focuses on service quality assessments and the gaps generated during the service process, which may fall into one of the five dimensions, namely, customer expectations, customer perception, delivery from the supplier, setting quality standards, and management awareness of quality, of which four are from the provider. The remaining one is from the customer, the gap between consumer expectation, and perception. The more consumer perception of service surpasses expectations, the higher the service quality is considered. From the perspective of how manufacturing affects quality improvement, the customer's concern is accuracy and precision. The evaluation index is equal to the square of value of the difference between the minimum average value and the target value adding the variance. Most past improvements focused on optimization within a certain range, but in recent years, the concept of first pass yield has been given extra attention. Six Sigma proposed this procedure-based framework. This research followed this idea, adopting the procedural framework in assessing the service gap between providers and consumers using SFMEA and C\&E matrix tools, and discovered the crux of service quality problems by analysing the service gaps.

The traditional retail appliance service industry in New Taipei City is an object of empirical research. By collecting customer information through questionnaires, this research explains the proposed analyses procedures, identifies key problems, and proposes corresponding improvement strategies. After 3 months of improvement, verifying the proposed method can effectively identify key service gaps.

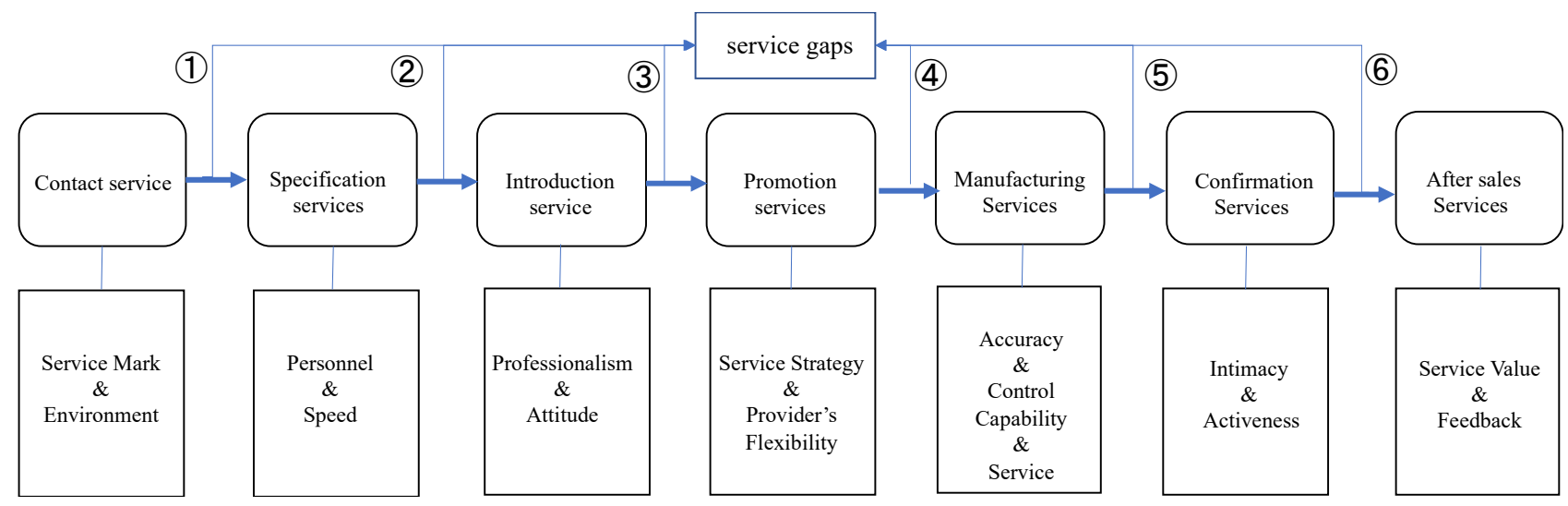

Figure 1. Service process framework and gaps

\section{Methodology}

\subsection{Research Framework}

This research proposed a framework for measuring service quality. With the help of information about inner providers and outer customers, service providers were able to adjust their programs for assessing service gaps according to this framework design. From the results of service gap analysis, we discovered the exact rate of service quality. When the service provided was better than expected by customers, it was considered good quality.

On the contrary, if the service provided did not meet expectations, then the service was considered a failure. This study assesses inner providers using SFMEA and outer customers using cause-and-effect ( $C \& E$ matrix) analyses, and then integrated the results of the two to arrive at the service gap index 
and determine whether the service quality was a success or a failure.

Service quality is an output of continuous activity. This study analysed the process in the service industry and defined seven significant activities. Figure 1 illustrates the service process and these seven steps.

\subsection{Service Failure-Mode-and-Effects Analysis (SFMEA)}

SFMEA was applied for analyzing the overall service process by identifying the problems and their potential causes. These problems may result in the emergence of service gaps, of which familiar service providers are ignorant. The most significant advantage of using SFMEA is that a problem can be effectively controlled and prevented before becoming a risk, and afterward remedial measures can be taken according to the degree of risk. Its only weakness is that it does not consider customers' desires, while the C\&E matrix mainly analyzes consumer demand by designing input and critical-to-quality (CTQ) diagrams and can calculate the most cared about service links based on scores assigned according to their importance to customers.

SFMEA is an extension of Failure-Mode-andEffects Analysis (FMEA), which is used to identify failures of products or manufacturing processes and devise ways to prevent those failures. Under this framework, this study proposes a way to assess invisible failures in the service process using SFMEA and influence service quality's influence on customer satisfaction. First, we consider the reasons for the occurrence of specific service procedures during implementation of service activities by means of questionnaires and specific diagrams. In doing so, we conducted an in-depth study of these procedures' impact on consumers and the degree, cause, occurrence frequency, and difficulty for service providers to discover when failures occur. The risk priority number (RPN) was then calculated based on the severity, occurrence frequency, and difficulty of inspection. Finally, for high RPNs, we presented preventive, and remedial methods that could be implemented to improve the quality and reliability of service processes. The implementation analysis steps are as follows:

Step 1 :

Gather data about service process operations.

Step 2 :

Identify service functions or units of the service process.

Step 3 :

Describe approximately the implementation of service steps.
Step 4 :

Draft an SFMEA table for analysis.

Step 5 :

Calculate RPN $(\mathrm{RPN}=$ Severity $\times$ Occurrence $\times$ Detection).

\subsection{Cause-and-Effect Matrix (C\&E matrix)}

The C\&E matrix is a matrix simplifying the Quality Function Deployment method. It is used to analyze variables affecting value results in the service process and determine their weight of importance to customers according to their degree of effect on the results. After setting up the weight coefficients, the correlation scores are assigned to variables by their strength in influencing the results. Last, correlation scores are cross-multiplied with priority scores and added across each step to find out, in which step the priority of the service process lies. C\&E matrix with the following six steps:

Step 1:

List the process steps according to the CTQ.

Step 2:

Rank and assign scores (1-10) to each output variable according to their importance to customers.

Step 3:

List the input variables according to the process steps.

Step 4:

Determine correlation scores for each input (Step 3) and CTQ (Step 1) based on the strength of their interrelationships (e.g., $1=$ weak, $3=$ some, $9=$ strong).

Step 5:

Cross-multiply correlation scores with priority scores and add across for each output.

Step 6:

Create a Pareto chart and focus on the key service processes and the potential causes with higher overall scores.

\subsection{Service Gaps Index}

This research assessed service gaps by combining SFMEA with a C\&E matrix. First, we standardized the respective scores of the questionnaires for the SFMEA and the C\&E matrix; then, we arrived at the quantified service gap index $\left(S_{\text {index }}\right)$ from the result of their subtraction. Whether the current service process belonged to success quality $\left(S_{\text {index }}>0\right)$ or failure quality $\left(S_{\text {index }}<0\right)$ was then determined according to this index. We then focused on the key causes according to the type of quality and discovered the main area that needed improvement. The service gap index was calculated using the following procedure: 
Step 1:

Standardize the numerical value of SFMEA by labeling projects in the service process as $Q_{i}, i=1,2, \ldots k$, and the corresponding result is $Z_{Q_{i}}$.

$$
\begin{gathered}
Z_{Q_{i}}=\frac{\left(\bar{x}_{Q_{i}}-\overline{\bar{x}}_{Q}\right)}{\hat{\sigma}_{Q}}, \\
\overline{\bar{x}}_{Q}=\sum_{i=1}^{k} \frac{\bar{x}_{Q_{i}}}{k}, \hat{\sigma}_{Q}=\frac{\bar{S}}{C_{4}}, \bar{S}=\sum_{i=1}^{k} \frac{S_{Q_{i}}}{k}
\end{gathered}
$$

Step 2:

Standardize the numerical value of the $C \& E$ matrix by labeling projects in the service process as $R_{i}, i=1,2, \ldots k$, and the corresponding result is $Z_{R_{i}}$.

$$
\begin{gathered}
Z_{R_{i}}=\frac{\left(\bar{X}_{R_{i}}-\overline{\bar{X}}_{R}\right)}{\hat{\sigma}_{R}}, \\
\overline{\bar{X}}_{R}=\sum_{i=1}^{k} \frac{\bar{X}_{R_{i}}}{k}, \hat{\sigma}_{R}=\frac{\bar{S}}{C_{4}}, \bar{S}=\sum_{i=1}^{k} \frac{S_{R_{i}}}{k}
\end{gathered}
$$

Step 3:

Define the service gap index ( $\left.S_{\text {index }}\right)$ by using $Z_{Q_{i}}$ and $Z_{R_{i}}$

$$
\begin{gathered}
S_{\text {index }}=\frac{\bar{d}}{S_{d}}, d_{i}=Z_{Q_{i}}-Z_{R_{i}}, \bar{d}=\sum_{i=1}^{k} \frac{d_{i}}{k} \\
S_{d}=\sum_{i=1}^{k} \frac{\left(d_{i}-\bar{d}\right)^{2}}{k-1}
\end{gathered}
$$

\section{Case Study Analysis and Discussion}

The data from the 150 external questionnaires conducted in New Taipei City were collected and analyzed. This study discusses and analyzes the existing problems in the traditional home appliance retail industry through the following two steps: first, by describing overall service using the standard service process framework, and second, by collecting the data from the 20-item questionnaires designed according to the service process perspective. The survey used an internal questionnaire for providers and an external for customers. The data from the former were analyzed using SFMEA, while data from the latter were processed using a C\&E matrix. The internal questionnaire was conducted during a staff meeting with 20 strong returns; the external questionnaire was conducted among customers in neighborhood retail stores, employees, and passersby, with 150 strong returns. Next, we calculated the Cronbach's $\alpha$ value to analyze the reliability of the questionnaire itself. The results are shown in Table 1. Cronbach's $\alpha$ values for the seven service aspects were all greater than 0.7 , indicating the data obtained by the questionnaire was representative.

We then calculated the service gap index based on the proposed calculator program. The calculation of the quantified service gap was $S_{\text {index }}=-0.66$, which indicates the retail industry showed a service quality failure. The results of further analysis are shown in Table 2, which found that in for the 11 questions for the SFMEA standardization were less than that of the C\&E matrix.

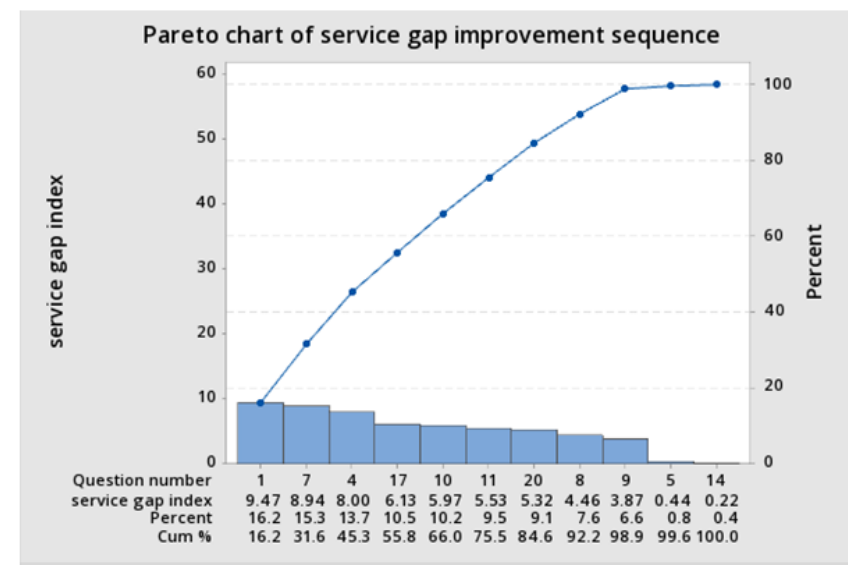

Figure 2. Pareto chart of service gap improvement sequence

Table 1. Cronbach's alpha value for the 20-item external questionnaire

\begin{tabular}{lc}
\hline \multicolumn{1}{c}{ The measurement significant activities of service processes } & Cronbach's $\alpha$ value \\
\hline Contact service & 0.859 \\
Specification services & 0.880 \\
Introduction service & 0.865 \\
Promotion services & 0.869 \\
Manufacturing Services & 0.899 \\
Confirmation service & 0.841 \\
After sales service & 0.801 \\
\hline
\end{tabular}

Next, for the results with negative service gap indices, the absolute values were taken to draw Plato's charts, as shown in Figure 2.

The priority order for improvement of the service gap is $1,7,4,17,10,11,20,8,9,5$, and 14 , respectively. Please refer to Table 4 for details on the questionnaire questions. These are key service processes that cause an overall service gap. In view of the above problems, the key points, and similar strategies proposed by this study are the following: 
- $\quad$ Recognition and clarity of shop signs.

Theoretically, it is incumbent upon the provider to keep their promises. But in practice, avoidance of disputes between customers and the provider requires the former to reach a service agreement before settling on service activities to maintain bondage between the two parts.

- $\quad$ Some service provider staff make light of customers.

Training staff should receive priority. Employee benefits should include a performance bonus that fosters employee belief; the more loyal they are to the company, the more they will get.
- $\quad$ Store location (including transportation convenience).

Add intimate customer pick-up service to compensate for any inconvenience caused by the location of the store.

- Whether the store is willing to cooperate with customers to accept related services or goods.

The time span for some services has hampered the provider's capacity to cooperate with the customer. Therefore, the provider should arrange the task properly, and before the execution, so they have enough time to help the customer with the acceptance check.

Table 2. Calculation result of service gap index in service process

\begin{tabular}{|c|c|c|c|c|c|}
\hline $\begin{array}{l}\text { Question } \\
\text { number }\end{array}$ & Service Process & Questionnaire Content & $Z_{Q}$ & $Z_{R}$ & $S_{\text {index }}$ \\
\hline 1 & Contact service & Recognition and clarity of shop signs & -10.15 & -0.68 & -9.47 \\
\hline 2 & Contact service & $\begin{array}{l}\text { Information about shop services on the Internet } \\
\text { (including price, evaluation) }\end{array}$ & 0.88 & 0.05 & 2.81 \\
\hline 3 & Contact service & Location of store service products & 4.22 & 0.10 & 6.35 \\
\hline 4 & Contact service & Store location (including transportation convenience) & 5.84 & -0.50 & -8.00 \\
\hline 5 & Contact service & $\begin{array}{l}\text { The environment inside the store (including } \\
\text { temperature, space, air, noise, lighting) }\end{array}$ & -5.58 & 0.39 & -0.44 \\
\hline 6 & Contact service & Store style features (including furnishings) & 0.26 & 0.14 & 6.49 \\
\hline 7 & Specification services & Is the store service staff neat, clean, and polite & 2.68 & -0.13 & -8.94 \\
\hline 8 & Specification services & $\begin{array}{l}\text { Whether store service staff can quickly respond to } \\
\text { customer requests }\end{array}$ & -4.14 & 0.32 & -4.46 \\
\hline 9 & Introduction service & $\begin{array}{l}\text { Stores have information about service products or } \\
\text { projects }\end{array}$ & -3.86 & 0.01 & -3.87 \\
\hline 10 & Introduction service & $\begin{array}{l}\text { Does the store service staff have a despise attitude } \\
\text { toward customers? }\end{array}$ & -0.26 & 0.17 & -5.97 \\
\hline 11 & Promotion services & $\begin{array}{l}\text { Whether the store can give proper advice and the right } \\
\text { concept }\end{array}$ & 6.21 & -0.28 & -5.53 \\
\hline 12 & Promotion services & $\begin{array}{l}\text { Does the store service staff have enough rights to give } \\
\text { customers a degree of concession? }\end{array}$ & -5.08 & 0.23 & 13.78 \\
\hline 13 & Manufacturing Services & $\begin{array}{l}\text { Does the store perform any changes to the agreed } \\
\text { service activity plan }\end{array}$ & -6.36 & -0.23 & 5.34 \\
\hline 14 & Manufacturing Services & Does the shop cut corners on service activities? & -5.58 & -0.05 & -0.22 \\
\hline 15 & Manufacturing Services & $\begin{array}{l}\text { Whether the store can complete the service project } \\
\text { within time }\end{array}$ & 0.07 & 0.29 & 0.82 \\
\hline 16 & Confirmation service & $\begin{array}{l}\text { Does the store actively provide information about after- } \\
\text { sales service? }\end{array}$ & 5.45 & 0.10 & 0.49 \\
\hline 17 & Confirmation service & $\begin{array}{l}\text { Whether the store is willing to cooperate with } \\
\text { customers to accept related services or goods }\end{array}$ & -7.98 & 0.01 & -6.13 \\
\hline 18 & Confirmation service & Are there any additional service charges at the store? & 0.33 & -0.15 & 4.12 \\
\hline 19 & After sales service & $\begin{array}{l}\text { Whether the store can solve the problem of after-sales } \\
\text { service products in the shortest time }\end{array}$ & 13.61 & -0.17 & 0.11 \\
\hline 20 & After sales service & $\begin{array}{l}\text { Does the store charge maintenance fees at will during } \\
\text { the warranty period? }\end{array}$ & -8.60 & 0.34 & -5.32 \\
\hline
\end{tabular}

- $\quad$ Service provider staff makes light of customers. Priority should be given to training staff. It is suggested that employee benefits should include a performance bonus that allows employees to believe that the more they work for the company, the more they will get.

- Providers do not offer the correct and proper advice.

The unprofessional service provider staff did not tell the correct concept to the customer. Therefore, the provider should train and educate their staff to prevent miscommunication which can cause a loss of customers.

- $\quad$ Providers charge the customer for the diagnosis and repair of products during the warranty period.

Within the warranty period, the provider will take full responsibility for product defects without any 
charges. Nevertheless, some providers will charge customers without any judgment about the source of the problem. Therefore, the provider should supervise their maintenance personnel to prevent arbitrary charges and guarantee the quality of the after-sales service.

- $\quad$ Store service staff cannot quickly respond to customer requests.

During the education and training, the ability of service personnel to appease customers should be strengthened to achieve a friendly service relationship.

- Stores do not have information about products or projects.

Classifying products and assigning them to full-time service personnel can reduce the error rate and provide customers with a more specialized analysis of products for making choices and consumption.

- $\quad$ Service staff is insufficiently tidy and wellmannered.

Well-mannered service staff is integral to the mood of the customer. The provider should also check their manner and, sometimes, their uniform and appearance.

- $\quad$ Providers cheat on workmanship and materials.

The provider sacrifices quality for profits, regardless of safety, and durability of service. Therefore, providers should consider the rights and interests of the customer and develop appropriate strategies rather than being driven by only profit.

- $\quad$ Service staff does not have enough right to offer customers discount.

To raise the popularity and expand sales volume, the provider launched a promotion or a sale; however, during this process, the customer would turn to others if their preferential terms are not attractive enough or products are not properly arranged. Therefore, the provider should ensure their staff has enough preferential counters to negotiate with the customer.

- $\quad$ Provider's advertising is unclear or easily identified.

Provider should keep their signboards simple and clear or substitute words for easily identifiable signs.

- The provider does not cooperate with customers to check products or service after delivery.

The provider should properly arrange the task time before execution so that they have enough time to help the customer.

\section{Conclusion}

This study provided a practical solution to evaluating service variations in service processes by using SFMEA and C\&E matrices to analyze and explore service gaps and quantify them to determine service improvement goals, with the ultimate goal of highlighting the unique advantages of traditional home appliance retailing. In conducting this research, we hoped to bring suppliers and consumers closer so that their needs are met. We also aimed to analyze service processes to understand specific issues and improve service quality.

Consumers are now under the environment of multivariate information. Traditional home appliance retailers for the hypermarket are like the relationship between a big whale and a little shrimp; a gap exists between the results of analysis. However, the traditional home appliance retailer has the advantage, so that the future of traditional home appliance retailers can still have a place in the market and part of customers' preferences for traditional home appliance retailers. Therefore, traditional home appliance retailers should bear in mind the existence of service gaps to attract consumers' attention by proposing effective improvement strategies and highlighting their unique characteristics.

\section{References}

[1]. Agarwal, R., Mehrotra, A., \& Barger, V. A. (2016). Personality Traits and Repatronage Intentions After Service Failure. Journal of Consumer Satisfaction, Dissatisfaction \& Complaining Behavior, 29.

[2]. Chen, C. F. (2008). Investigating structural relationships between service quality, perceived value, satisfaction, and behavioral intentions for air passengers: Evidence from Taiwan. Transportation Research Part A: Policy and Practice, 42(4), 709717.

[3]. Goetsch, D. L. \& Davis, S. (1994). Introduction to total quality: Quality, productivity, competitiveness. Prentice-Hall International Edition.

[4]. Klischewski, R., \& Wetzel, I. (2000). Serviceflow Management. Informatik Spektrum, 23(1), 38-46.

[5]. Kavunder, A., \& Koodli, R. (2017). U.S. Patent No. 9,661,522. Washington, DC: U.S. Patent and Trademark Office.

[6]. Lovelock, C. H. (1991). Developing frameworks for understanding service marketing. Services marketing. New Jersey: Prentice-Hall.

[7]. Montagna, J. M. (2005). A framework for the assessment and analysis of electronic government proposals. Electronic commerce research and applications, 4(3), 204-219.

[8]. Morales Bezeira, A., Villapol, M., Scalise, E., Naranjo, C., \& Álvarez, F. (2017). Analysis of the Dynamic Service Flow Management Transactions Protocol for MAC IEEE 802.16. An Aproach. In Simposio Latinoamericano de Infraestructura, Hardware y Software (SLIHS)-JAIIO 46 (Córdoba, 2017).

[9]. Parasuraman, A., Zeithaml, V. A., \& Berry, L. L. (1988). Servqual: A multiple-item scale for measuring consumer perc. Journal of retailing, 64(1), 12-40.

[10]. Porter, M. E. (1985). Competitive advantage: creating and sustaining superior performance P33 The Free Press. New York, NY. 